\title{
LXII. On the theory of magnetic electricity
}

\section{Mr. Wm. Sturgeon}

To cite this article: Mr. Wm. Sturgeon (1833) LXII. On the theory of magnetic electricity, Philosophical Magazine Series 3, 2:11, 366-371, DOI: 10.1080/14786443308648060

To link to this article: http://dx.doi.org/10.1080/14786443308648060

册Published online: 01 Jun 2009.

Submit your article to this journal 준

LII Article views: 4

Q View related articles $₫$ 
LXII. On the Theory of Magnetic Electricity. By Mr. WM. Sturgeon, Member of the British Association for the Promotion of Science; Lecturer at the Hon. East India Company's Military Academy, Addiscombe, \&c. \& c.

[Continued from p. 207.]

$\mathrm{T}$ is probable, however, that other laws are in operation during this novel process of excitation, which are still more remotely situated from observation; and require for their development, experiments and a mode of reasoning of a very different order to those which have been employed for organizing the system of proximate laws already explained.

It appears to me that electric currents generated by magnetic agency are not the immediate effects of the magnet employed in the excitation. It is highly probable that there is a mediate or intervening agent called forth; - the magnetism natural to the excited metal, which, by being polarized by the exciting polar magnetic lines of the magnet, becomes the immediate agent in giving life and energy to the previously dormant electricity of the metal.

Remote and mysterious as the intermediate agency of the natural magnetism of the metal in this process of exciting electricity may appear in the present infantile stage of the science, I have much reason to suppose that such is the fact. The phænomena in magnetic-electricity, as well as those in electro-magnetism, are highly favourable to the hypothesis; and I am not aware of an exception that militates directly against it. Moreover, the facility with which the modus operandi might be explained upon the simple principles of polar magnetic lines alone, would, I am persuaded, establish a degree of plausibility at least, not easily shaken by any counter-reasoning likely to be advanced; and the illustrations which it would be possible to bring forward in support of such an hypothesis, might possibly be the means of fixing a basis on which the theory of excitation in this curious branch of physics is eventually and permanently to be established.

The same class of remote laws apply equally to electromagnetism as to magnetic-electricity; and it would be very difficult, indeed, independently of those laws, to completely harmonize with each other the phænomena displayed by the two different modes of excitation.

With regard to electro-magnetic action, the idea can hardly be said to be novel. Mr. Buxton long ago asserted that the magnetism of the conducting wire becomes polarized, and is the intermediate agent between the transmitted electric cur- 
rent and the magnet employed; but the illustrations which have been advanced by that gentleman might possibly require considerable moditication to establish a theory on those principles.

I have heard brought forward, as an argument against the hypothesis of magnetic polarity of the conducting wire, an experiment of Sir H. Davy's, which showed the deflection of an electric current passing through air between the charcoal points of a voltaic battery, by. the presentation of a magnetic pole. Such arguments can have but very little force in discussions of this character; for the experiment develops nothing different to the generality of electro-magnetic phænomena. If an electric current be capable of rousing into activity the dormant magnetic powers of ferruginous matter, no doubt can possibly be entertained of its susceptibility of being put into motion by the energies of an already formidable polarized bar.

This is the extent of reasoning to which the experiment can be applied even under the supposition of the electric current being the immediate agent in the process of magnetizing iron or steel, and that no intervening polarization of the conducting wire is concerned in the operation; which, in fact, is no argument whatever, further than might be advanced from any other electro-magnetic experiment.

On the other hand, it might be inferred with a great deal of propriety, that if the electric current is capable of calling forth the latent magnetism of hard steel, in which it is pent up and retained with a degree of vigour which requires the greatest efforts of the exciting agent to extricate it and accomplish its polarity even to a comparatively small extent;-it is but reasonable to expect that in those metals which do not possess so exalted a degree of retention as hard steel, the same exciting agent would accomplish a polarity to a much greater extent.

This simple induction is beautifully illustrated and substantiated by demonstrable facts, by comparative experiments on soft iron and hard steel; and it was by the same mode of reasoning that I was first led to construct electro-magnets of soft iron*; since which time the practice has been pursued with more than anticipated success.

The facility of polarizing the magnetic matter, or of arranging it into active polar lines by any constant exciting force, appears to be inversely proportional to the retentive quality of the metal on which the process is performed.

* See Transactions of the Society of Arts, \&c. vol. xliii.; Phil. Mag. and Annals, N.S., vol. xi. p. 194. 


\section{$368 \mathrm{Mr}$. W. Sturgeon on the Theory of Magnetic Electricity.}

The retention of magnetic polarity is displayed to the greatest extent by very hard steel. After this the retentive faculty diminishes with various grades of hardness down to soft steel; thence by gradations downwards to the softest iron, which exhibits the faculty of retaining magnetic polarity, only in a very slight degree indeed. But the facility of magnetizing those bodies, and the extent to which their polarity is exhibited, are in precisely the reverse order.

Now, as the retention of polarity appears to result from a want of facility, on the part of the metal, to readmit the magnetic matter which the exciting agent has arranged into active polar lines on its surface and vicinal medium; and as those metals which display the retentive faculty in the greatest degree also offer the greatest resistance to the formation of those polar lines, or to the escape of the magnetic matter from its ferruginous prison;-this disposition evinced by the metal, of resisting both the egress and ingress of the magnetic matter, must necessarily arise from a natural tendency which it possesses to refuse the transmission of the magnetic element. Hence those metals which retain magnetic polarity in the highest degree may be called inferior magnetic conductors; and those which retain no traces of polarity after the exciting process has ceased to operate, may be called superior magnetic conductors, with as much propriety, and for the same reason, as similar terms are employed in electricity.

Under these considerations it will appear that hard steel is an exceedingly bad conductor of magnetism; because it offers a very great resistance to the motion of the magnetic matter. This resistance causes the process of magnetizing to become exceedingly tedious; and with very hard cast steel it very seldom terminates suceessfully, or to the satisfaction of the operator. Hence, in a practical point of view, it is interesting to know that magnets constructed of cast steel should never be harder than the blue temper.

Soft iron being the best ferruginous conductor of magnetism, offers a much less resistance to the flow of the magnetic matter than when in any other state. The vigorous polar magnetic lines are therefore speedily arranged, and to an extent of concentration never to be accomplished on the surface of very hard steel.

But the same conducting quality which gives to soft iron a facility of excitation, also gives a facility to the return of the magnetic matter into the metal when the exciting agent is withdrawn; for which reason the retention of polarity displayed by soft iron is exceedingly feeble, and easily deranged.

Hence it appears that, as far as ferruginous bodies are con- 
cerned, the vigorous retention of magnetic polarity exhibited by some of them, and the almost total absence of this quality in others, may very easily be explained upon the principles already advanced; and perhaps it would only require that we should consider copper and other non-ferruginous metals to be still better magnetic conductors than soft iron, to reconcile the sudden and total disappearance of polarity in them to the same principles, whether the exciting agent be magnetic or electric.

I have deflected a magnetic needle by an electric current traversing an ignited charcoal conductor, as was first shown by the very interesting experiments of $\mathrm{Mr}$. Kemp; but as we are not aware of the total absence of the magnetic matter in charcoal, the experiment is inconclusive, any further than as an interesting fact, which has no particular bearing on the present discussion.

The energies of ferruginous electro-magnets are invariably exalted by multiplying, to a certain extent, the number of coils of conducting wire. My large electro-magnet, described in a former communication, requires twelve coils to accomplish its maximum of power ( 400 pounds). The general explanation of this fact is, I believe, that one wire alone is incapable of transmitting or conducting the whole of the electric force; and therefore a multiplicity of conducting wires becomes necessary in order that the battery may be enabled to give a full and complete display of its electric energies. And in orler to accomplish this object the more completely, the extremities of all the wires are brought as close as possible to the voltaic plates. The wires of the large American magnet are even soldered to the plates of the battery.

I find, however, that although an addition of coils is attended with an accession of magnetic power until a maximum of polarity is accomplished, it is by no means essential that all those wires arrive immediately at the battery. A single copper wire may intervene between the coils round the iron and the poles of the battery without deteriorating the energies of the magnet, which will still be displayed to a maximum, as decidedly as if the whole system of wires were soldered directly to the plates.

My large electro-magnet is still capable of supporting its 400 pounds, notwithstanding the electric force has to traverse six inches of bell-wire before it arrives at the coils; and also six inches more from its quitting the coils till its arrival at the other pole of the battery; -in all, twelve inches of single bellwire. There is a limit, however, to the dimensions of the intervening wires. If they be too long or too thin, the magnet

Third Series. Vol. 2. No. 11. May $1833 . \quad 3 \mathrm{~B}$ 
will not display its maximum of power. With pretty stout bell-wire, and the length not exceeding twelve inches, I always succeed. The battery which I employ is a single pair of metals, sufficiently small to be placed in a pint pot.

This novel and curious fact is one of those which bears directly on the subject in question, and in a theoretical point of view is of a most interesting character. In practice, also, I find that it is exceedingly useful ; giving a facility of manipulation so desirable in the management of very large electromagnets, but which is not to be expected when all the extremities of the wires arrive immediately at the copper and zinc.

The theory of polar magnetic lines which I have advanced, requires not two magnetic fluids, nor indeed is it fuvourable to that doctrine; and if it be not fatal to the circulating currents of Ampère, it will at least require them to be in motion in a great variety of planes, which that distinguished philosopher never intended they should pursue. It is possible, however, that electric currents are naturally attended with magnetic polarity, independently of that which has been supposed to be excited in the wire; but it is by no means so probable that the existence of magnetic polarity is universally due to the permanency of electric currents. Electric currents may very possibly, either directly or indirectly, magnetize the terrestrial globe; but we have no reason whatever to believe that such currents are essential to give retention of polarity to steel.

The introduction of polar masnetic lines into the theory of electro-magnetism would simplify the explanation of the phænomena, and reduce them to the principles of magnetics; and experiments may be shown in both sciences which are favourable to such a conclusion, independently of any consideration that would reconcile to identity the electric and magnetic matter.

If it can be admitted as an universal maxim in nature, that when one species of matter is impregnated with, contains, or is charged with another, the charged body must necessarily be of a grosser texture than the substance with which it is charged, or that the latter should be more subtle than the former; then it is possible that the magnetic matter, which is the most subtle we are acquainted with in nature, may insinuate itself into the pores of the electric; and the latter become charged with the former, as decidedly, under some circumstances, as a piece of iron is naturally charged with them both.

I shall not, however, on the present occasion, advance further into speculative suppositions of this kind, which, however curious they may appear in themselves, are perhaps not of 
much interest in the present stage of our knowledge of physical operations.

[To be continued.]

LXIII. Note on Mr. Potter's Reply. By William R. HAmilton, Esq. Andrews' Professor of Astronomy in the University of Dublin, and Royal Astronomer of Ireland*.

FROM Mr. Potter's Reply, published in the April Number of the London and Edinburgh Philosophical Magazine, I collect some additional facts respecting his experiment of prismatic interference, which do not seem to have been stated in his first account of that experiment. In Mr. Potter's first paper, the stress of his objection to the undulatory theory of light seemed to be laid on the observed direction of a certain deviation; to which he opposed his calculated decrease of a certain hyperbolic ordinate. I showed that this observed fact, of deviation in the observed direction (towards the thickness of the prism), could be accounted for by the prismatic aberration of figure, which changed the decreasing hyperbolic ordinate to an increasing ordinate of a certain other curve. But I was of course aware that this prismatic aberration, though a cause acting in the observed direction, might not be energetic enough to account for the whole, or even for the greatest part of the observed effect; and that whether aberration was, or was not, an adequate as well as a real cause (on the undulatory theory of light), must depend on the comparison of my calculated formulæ with the observed magnitude of the deviation, of which Mr. Potter had not given any measure, or even any estimate. I am happy to have been the means of inducing Mr. Potter to bring forward some additional testimony on this important point : and willingly admit, that according to this new testimony, there remains, after allowing for my suggestions, a large residual phænomenon.

Dublin, April 13, 1833.

LXIV. Revieros, and Notices respecting Nerw Books.

Journal of the Asiatic Society of Calcutta, Nos. 1, 2, and 3 ; with Plates. Calcutta, 1832.

W ${ }^{\mathrm{E}}$ are particularlydesirous of calling the attention of our readers to this valuable monthly periodical, which we are afraid is by no means so well known in Europe as its merits entitle it to be. The present Numbers form the continuation of a scientific journal, published also

* Communicated by the Author.

$3 \mathrm{~B} 2$ 